\title{
PELATIHAN PEMBUATAN PETA DIGITAL BERBASIS OPENSTREETMAP DI SMU PRISMA MANADO
}

\author{
Joyce Christian Kumaat \\ Program Studi Geografi, Fakultas Ilmu Sosial, Universitas Negeri Manado \\ joykekumaat@unima.ac.id
}

\begin{abstract}
One of the responsibilities of universities as stipulated in the Tridharma of college is the academic responsibility, including in this responsibility is to follow the development of science. The form of lecturer's responsibility in implementing the college Tridharma for the benefit of society is the dedication to society. Community service is considered necessary as a means to bridge the campus with the community. As the realization of the implementation of community service for lecturers Geography is an effort to improve the ability of educators, especially students who learn Geography subjects where, learning certain Geography materials have been very dynamic. Learning new materials in the field of geography, especially in the field of Geographic Information Systems (GIS) which can now integrate to obtain information or new theory. To improve students' ability in the field of Geography study at SMU, it is deemed necessary for lecturers of geography to conduct training for students in high school which is packaged in community service or science and technology package for the community (IbM) by lecturer of Geography Faculty of Social Sciences (FIS), State Manado State University. During the preparation for one month, also prepared the trainers and the device. Equipment used in the form of Global Positioning System (GPS), stationery, and computer equipment and software for demonstration drawing maps. The approach method used in this activity is a pragmatic-thematic practical approach and a theoretical pragmatic approach. The lecture method is necessary because the concept is an entirely new subject for the participants. After the participants are familiar with the basic concepts of Geographic Information System, there is a question and answer session to deepen the material. The method of learning in this activity is by the method of practice, assignment, and reporting results. Evaluation of learning outcomes can be seen from the practicum report conducted by the participants.
\end{abstract}

Keywords: geography, OpenStreetMap, science, technology, IbM.

\section{PENDAHULUAN}

\section{Analisis Situasi}

Salah satu tanggung jawab perguruan tinggi yang tertuang dalam tridharma perguruan tinggi adalah tanggung jawab akademis, termasuk dalam tanggung jawab ini adalah mengikuti perkembangan ilmu pengetahuan (sains). Universitas Negeri Manado (UNIMA) sebagai lembaga yang bertugas mendidik calon pendidik perlu menjaga kualitas pendidikan melalui peningkatan kualitas pendidiknya. Perkembangan sains yang pesat mengharuskan para pendidik untuk melakukan perubahan materi pembelajaran di lembaga-lembaga pendidikan/sekolahsekolah. Materi pembelajaran ini sangat pesat perkembangannya seiring dengan perkembangan teknologi informasi adalah bidang ilmu Geografi. Perkembangan ilmu Geografi terutama pada cabang Geografi Teknik, yakni Penginderaan Jauh, Kartografi dan Sistem Informasi Geografis. Perkembangan geografi teknik terutama didukung oleh perkembangan di bidang komputer dan periperalnya.

Tanggung jawab dosen dalam melaksanakan tridharma perguruan tinggi untuk kepentingan masyarakat adalah pengabdian pada masyarakat. Pengabdian 
pada masyarakat dipandang perlu dilakukan sebagai sarana untuk menjembatani kampus dengan masyarakat. Sebagai realisasi pelaksanaan pengabdian masyarakat bagi dosen-dosen Prodi Geografi adalah upaya peningkatan kemampuan pendidik, terlebih khusus siswa-siswa yang belajar mata pelajaran Geografi yang mana pembelajaran materimateri Geografi tertentu sudah sangat dinamis. Pembelajaran materi-materi baru di bidang ilmu geografi, khususnya dalam
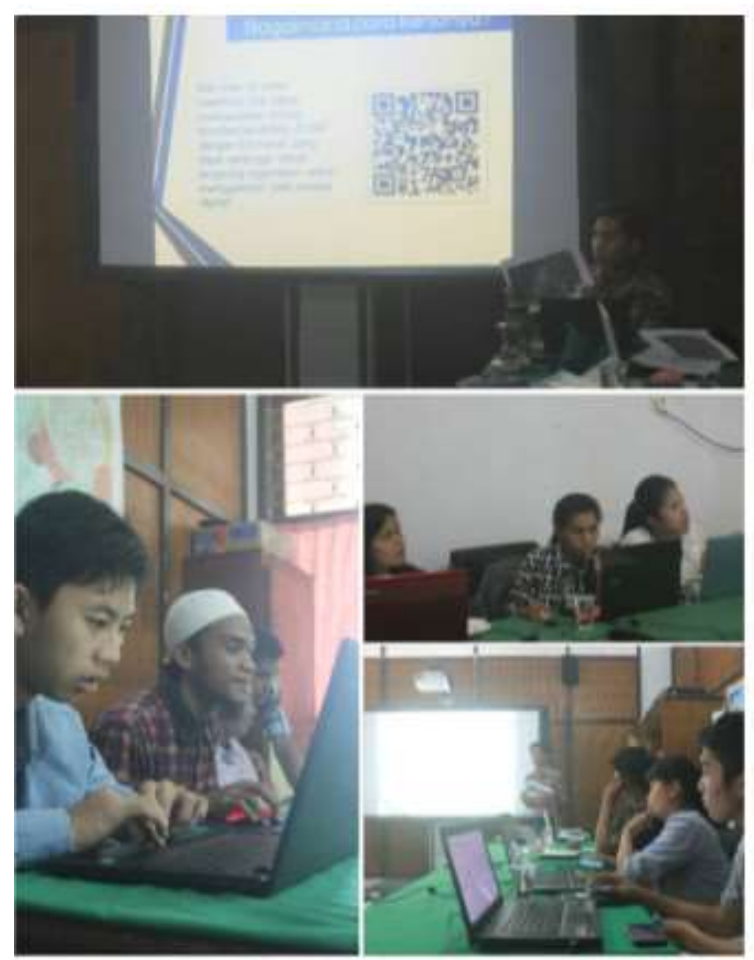

Gambar 1. Pelatihan pemetaan OpenStreetMap di Jurusan Geografi UNIMA.

Persoalan yang cukup merisaukan dikalangan para guru geografi, terutama guru-guru SMU adalah kesulitan dalam pembelajaran Sistem Informasi Geografi setelah dimasukkannya materi tersebut dalam kurikulum Mata Pelajaran Geografi SMU. Hal ini terjadi karena, mereka yang 10 bidang Sistem Informasi Geografis (SIG) yang kini dapat berintegrasi untuk memperoleh informasi atau teori baru. Untuk meningkatkan kemampuan siswa pada bidang studi Geografi di SMU maka dipandang perlu bagi dosen-dosen geografi untuk melakukan pelatihan bagi siswasiswa di SMU yang dikemas dalam paket pengabdian masyarakat atau Iptek bagi Masyarakat (IbM) oleh tim dosen Program Studi Geografi Fakultas Ilmu Sosial (FIS) Universitas Negeri Manado.
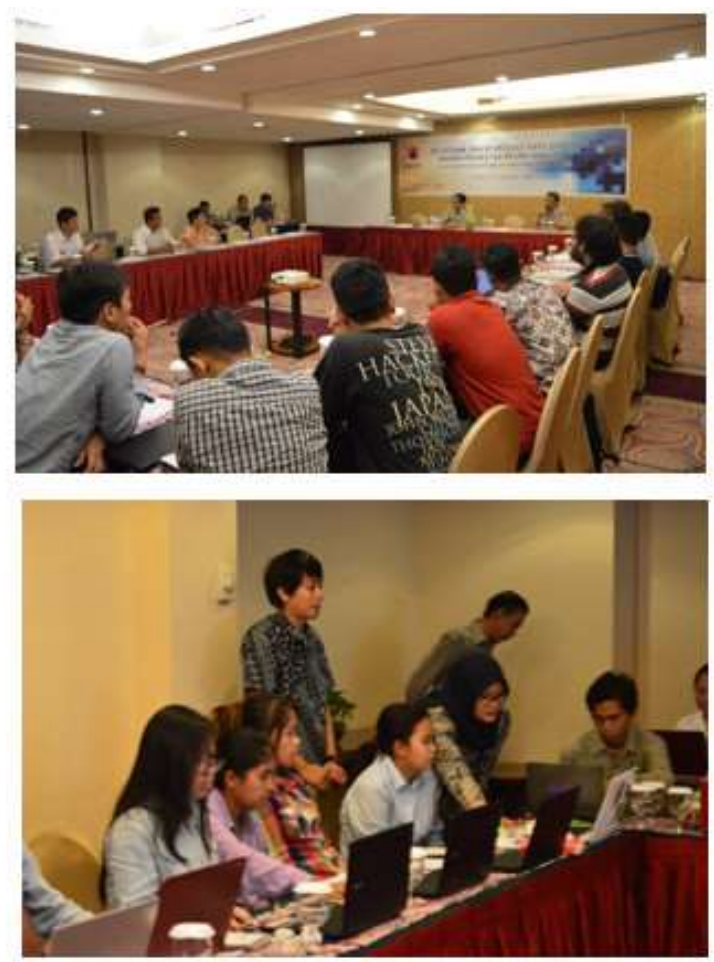

kini menjadi guru geografi belum pernah memperoleh materi tersebut ketika mereka kuliah dahulu, terutama para guru lulus sebelum tahun 1994 (kira-kira angkatan 1990 dan sebelumnya) karena memang saat itu mata kuliah Sistem Informasi Geografi belum diajarkan kepada mahasiswa 
pendidikan Geografi, ditambah lagi pada kurikulum SMU belum ada pelajaran tentang materi tersebut, sehingga banyak di antara mahasiswa yang tidak mengambil mata kuliah Sistem Informasi Geografis.

Masuknya materi Sistem Informasi Geografis pada kurikulum Geografi SMU meupakan konsekuensi dari pesatnya perkembangan materi teknik dalam geografi. Apalagi kini proyeksi peta dan interpretasi hasil interpretasi citra dapat diintegrasikan, sehingga informasi dapat diperoleh secara lebih mudah. Bagi mereka yang tidak mengikuti perkembangan teknikteknik pemetaan akan jauh tertinggal. Bukan kesalahan Jurusan Geografi FIS UNIMA sebagai produsen guru, tetapi lebih kepada perkembangan ilmu itu sendiri.

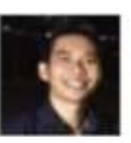

Biondi Sanda Sima shared his post to the group: Komunitas OpenStreetMap dan InaSAFE Manado.

November 28 at $4: 43 \mathrm{pm} \cdot 0$

\section{Ada kegiatan pemetaan UNIMA disebut di berita Jakarta Globe. Congrats and spread the good news!}

Biondi Sanda Sima shared The Jakarta Globe's post to the group: Komunitas

OpenStreetMap Indonesia.

November 28 at $4: 14 \mathrm{pm}$ - c

Acara \#OSMGeoWeek diliput oleh The Jakarta Globe. Baca selengkapnya di pranala berikut. Tulisan selengkapnya bisa juga dibaca di sini:

http://openstreetmap.id/.../boosting-spatial-data-awareness-.../

\section{\#OpenStreetMap \#InaSAFE \#InAWARE}

Gambar 2. Kegiatan Geography Awarness dari Tim Mapathon Geografi Unima di muat oleh media online Jakarta Globe.

\section{Permasalahan Mitra}

Berdasarkan analisis situasi yang telah dipaparkan di atas, maka dapat disusun rumusan masalah sebagai berikut:

1. Materi-materi Sistem Informasi Geografis khususnya pemetaan berbasis digital openstreetmap yang perlu dikuasai oleh para siswa?

2. Bagaimana cara yang harus dilakukan agar para siswa mampu mengerti konsep-konsep Sistem Informasi Geografis dengan openstreetmap yang mudah tanpa harus menggunakan peralatan yang canggih yang mahal?

3. Bagaimana usaha yang perlu dilakukan agar para siswa dapat menunjukkan pentingnya terapan materi Sistem Informasi Geografis dalam proses pembuatan peta digital kebencanaan dengan openstreetmap? 


\section{Solusi dan Target Luaran}

Adapun solusi dan target luaran dari kegiatan pelatihan materi Sistem Informasi
Geografis bagi para siswa-siswa SMU ini dapat dilihat dalam Tabel 1 berikut ini.

Tabel 1. Target luaran program pengabdian masyarakat kelompok siswa di SMU Prisma Manado.

\begin{tabular}{|llll|}
\hline No & Produk & Spesirikasi & Target \\
\hline $\mathbf{1}$ & $\begin{array}{l}\text { Para siswa mengusai materi-materi } \\
\text { pemetaan digital openstreetmap }\end{array}$ & $\begin{array}{l}\text { Penguasaan software } \\
\text { OSM }\end{array}$ & $\begin{array}{l}\text { Bisa membuat layout } \\
\text { peta dari OSM }\end{array}$ \\
\hline $\mathbf{2}$ & $\begin{array}{l}\text { Para siswa mampu memetakan daerah } \\
\text { rawan bencana dengan } \text { openstreetmap } \\
\text { secara mudah tanpa harus menggunakan } \\
\text { peralatan yang canggih dan mahal }\end{array}$ & $\begin{array}{l}\text { Penguasaan Java } \\
\text { Openstreet Map } \\
\text { (JOSM) }\end{array}$ & $\begin{array}{l}\text { Bisa membuat } \\
\text { database berbasis } \\
\text { geospasial }\end{array}$ \\
\hline $\mathbf{3}$ & $\begin{array}{l}\text { Para siswa mampu menggunakan field } \\
\text { paper sebagai bagian dari pengecekan } \\
\text { dilapangan atau Ground Truth }\end{array}$ & $\begin{array}{l}\text { Penguasaan Global } \\
\text { Positioning System }\end{array}$ & $\begin{array}{l}\text { Bisa membagi } \\
\text { wilayah-wilayah } \\
\text { yang di survey di } \\
\text { dalam field paper }\end{array}$ \\
\hline $\mathbf{4}$ & $\begin{array}{l}\text { Para siswa dapat melakukan penerapan } \\
\text { pemetaan } \text { openstreetmap kawasan rawan } \\
\text { bencana di Kota Manado }\end{array}$ & $\begin{array}{l}\text { Penguasaan } \\
\text { OSM,JOSM,GPS, } \\
\text { Field paper }\end{array}$ & $\begin{array}{l}\text { Peta tematik rawan } \\
\text { bencana kota Manado } \\
\text { lewat kegiatan } \\
\text { Mapathon }\end{array}$ \\
\hline
\end{tabular}

\section{METODE PELAKSANAAN}

\section{Tahap Persiapan}

Pada tahap ini kegiatan yang dilakukan adalah merencanakan peserta yang akan dundang. Dalam hal ini para guru siswa SMU. Selama persiapan selama satu bulan, dipersiapkan juga para pelatih serta perangkatnya. Jumlah pelatih sebanyak empat (4) orang. Peralatan yang digunakan berupa Global Positioning System (GPS), alat tulis menilis, maupun peralatan komputer serta perangkat lunaknya untuk demosntrasi menggambar peta. Metode pendekatan yang digunakan dalam kegiatan ini adalah pendekatan praktis pragmatistematis dan pendekatan pragmatis teoritis.

\section{Metode Pendekatan Pragmatis Teoritis}

Metode pendekatan ini dimaksudkan agar materi Sistem Informasi Geografis 12 yang begitu luas tidak menyebabkan keengganan untuk mempelajarinya. Untuk itu perlu dipilihkan materi-materi dasar dan penting untuk ditransformasikan kepada para siswa SMU, paling tidak memenuhi target kurikulum geografi SMU. Materi ini nantinya disampaikan dengan metode ceramah, tanya jawab, demonstrasi dan diskusi . Metode ceramah diperlukan karena konsep ini merupakan materi yang sama sekali baru bagi peserta. Setelah peserta mengenal konsep-konsep dasar Sistem Informasi Geografis baru diadakan tanya jawab untuk memperdalam materi.

\section{Tahap Pelaksanaan}

Ada dua model kegiatan yang akan dilaksanakan dalam acara ini, yakni : (1) acara ceramah, tanya jawab dan diskusi tentang materi SIG dan (2) praktikum SIG 
Jurnal ABDIMAS, Vol. 11, No. 1, April 2018

ISSN: 1979-0953 | e-ISSN: 2598-6066

(input data, editing, dan printing). Masingmasing kegiatan (mapathon) yang direncanakan sebagai berikut:

(1) Pengenalan Openstreetmap

(2) Pengenalan Java Openstreetmap (JOSM)

(3) Pemahaman aplikasi Sistem Informasi Geografis

(4) Praktikum penggunaan Global Positioning System (GPS)

(5) Perekaman data dengan Openstreetmap Tracker

(6) Bekerja dengan Field Paper

(7) Pengolahan data peta digital

(8) Evaluasi hasil belajar/praktikum

\section{Output}

Pelatihan ini memberikan suatu stimulant kepada siswa-siswa SMU khususnya di SMU Prisma Manado dimana hasil akhir dari pelatihan ini diharapkan siswa pada mata pelajaran Geografi sudah dapat membuat peta visualisasi yaitu peta digital berbasis sistem informasi geografis kepada siswa dengan perangkat lunak QGIS (Quantum GIS) dan JSOM (Java Opensteet Map). Selanjutnya pemberian modul di dalam pelatihan ini memberikan pijakan dasar dalam melakukan proses belajar mengajar dengan siswa. Selain itu, pemberian sertifikat (tingkat dasar) akan memberikan rasa percaya diri di dalam pengembangan sistem informasi geograsi sehingga dapat mensosialisasikan kepada murid dan masyarakat lainnya pentingnya peta digital di dalam perencanaan dan pemanfaannya untuk pembangunan yang berkelanjutan.

\section{HASIL DAN PEMBAHASAN}

Kegiatan Pelatihan OpenStreetMap di SMU Prisma Manado ini merupakan bagian dari kegiatan Pengabdian pada Masyarakat yaitu Ipteks berbasis pada Masyarakat. Tujuan dari kegiatan ini adalah untuk membentuk komunitas di daerah tersebut dalam mengenal lebih dalam tentang OpenStreetMap dan QGIS serta InaSAFE dan dapat membantu Badan Penanggulangan Bencana Daerah (BPBD) di daerah mereka masing-masing sebagai data collector ataupun data analyst. Pelatihan di SMU Prisma Manado ini merupakan pelatihan pertama kali di Sulawesi Utara di luar kampus Universitas Negeri Manado. Pelatihan diselenggarakan dalam 2 hari dan dimulai dari hari Rabu, 30 Agustus 2017 dan berakhir pada hari Kamis, 31 Agustus 2017. Pelatihan dibuka oleh Bapak La Diman selaku Guru Geografi dari SMU Prisma Manado dan dilanjutkan oleh materi pertama tentang perkenalan Rencana Kontinjensi serta Sistem Informasi Geografis (SIG). Setelah para peserta mendapatkan materi Rencana Kontinjensi mereka diharapkan sudah mengetahui maksud dari rangkaian kegiatan ini dan tujuannya terhadap diri mereka dalam mengikuti pelatihan ini selain itu dengan mempelajari Sistem Informasi Geografi mereka paham posisi OpenStreetMap sebagai data collector dan QGIS serta InaSAFE sebagai data processor sehingga mereka memahami alur rangkaian pelatihan yang akan mereka lakukan. 


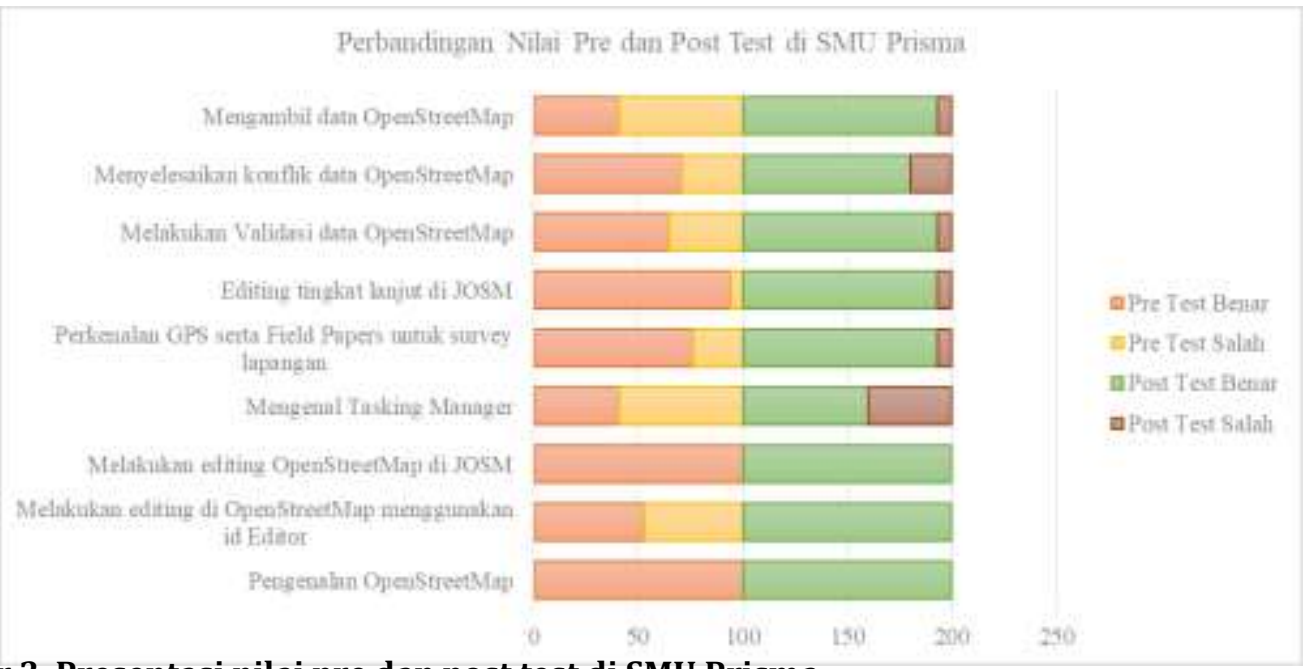

Gambar 3. Presentasi nilai pre dan post test di SMU Prisma.

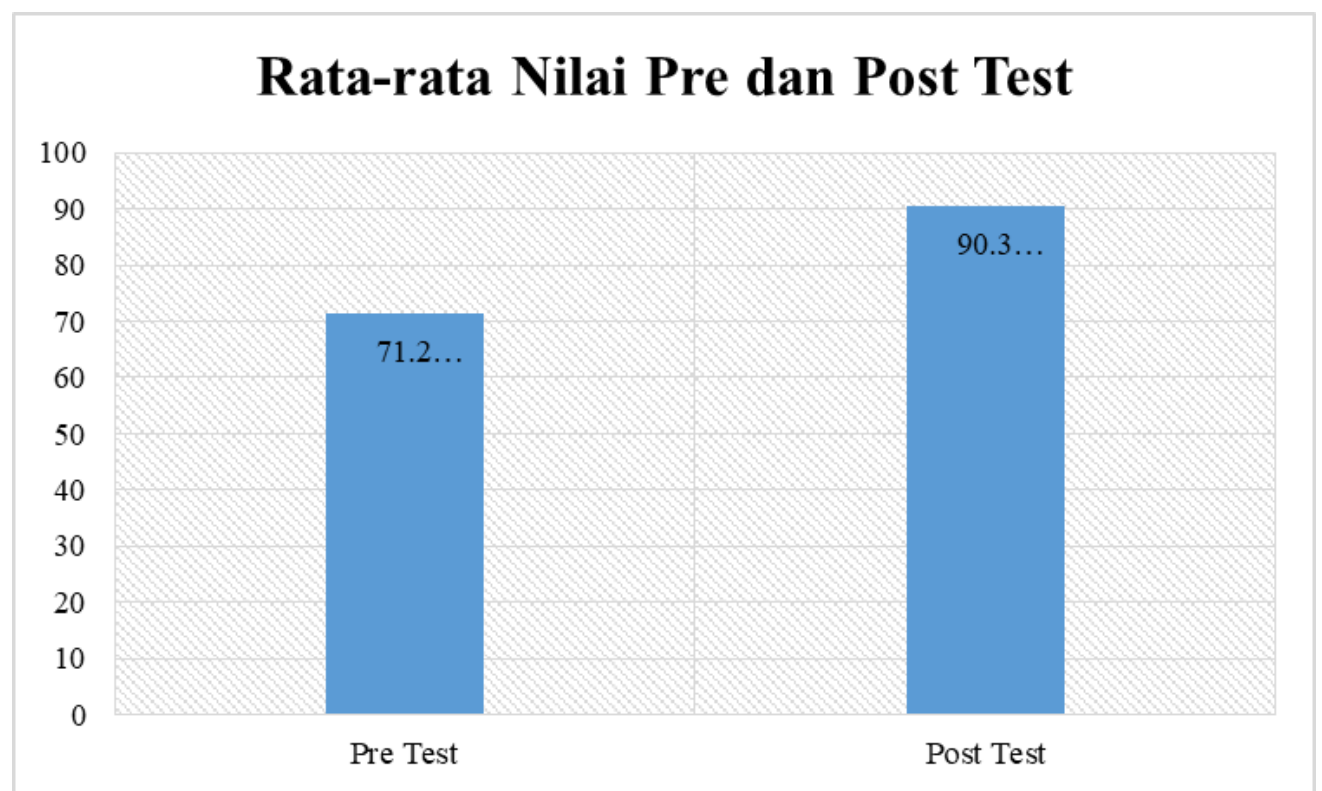

Gambar 4. Rata-rata nilai pre dan post test di SMU Prisma.

Setelah para peserta sudah memahami konsep Rencana Kontinjensi serta Sistem Informasi Geografis, materi kemudian masuk ke dalam materi pengenalan OpenStreetMap dan cara melakukan survey lapangan untuk mengumpulkan data. Materi OpenStreetMap terdiri dari beberapa bagian yaitu:

a) Pengenalan OpenStreetMap

b) Melakukan editing di OpenStreetMap menggunakan id Editor c) Melakukan editing OpenStreetMap di JOSM

d) Mengenal Tasking Manager

e) Perkenalan GPS serta Field Papers untuk survey lapangan

f) Editing tingkat lanjut di JOSM

g) Melakukan Validasi data OpenStreetMap

h) Menyelesaikan konflik data OpenStreetMap

i) Mengambil data OpenStreetMap 


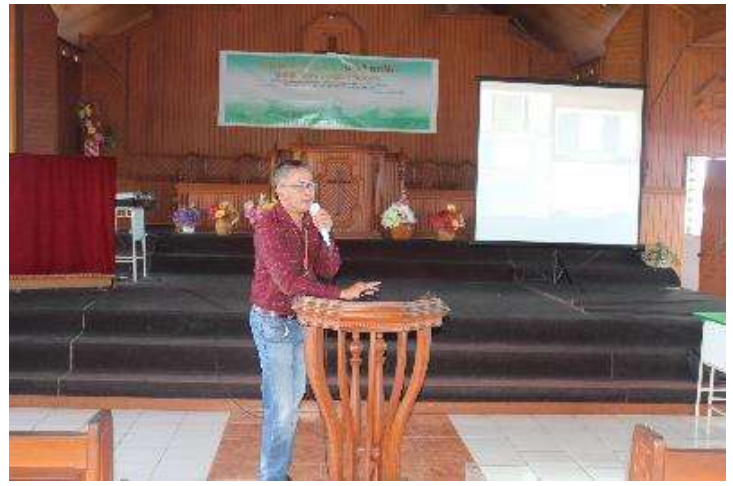

Gambar 5. Penyampaian materi pengenalan OpenStreetMap untuk siswa tangguh bencana.

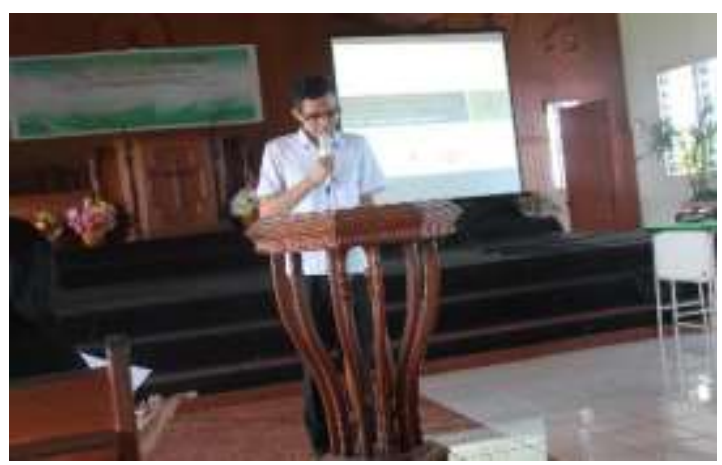

Gambar 6. Penyampaian dari pihak sekolah di dalam mendukung kegiatan OpenStreetMap.

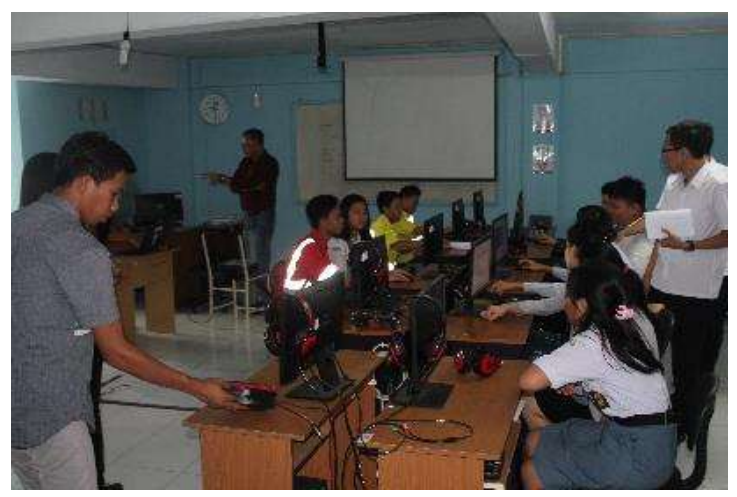

Gambar 7. Kegiatan di laboratorium pengenalan OpenStreetMap.

Pada hari Kamis, 31 Agustus 2017 dilaksanakan survei lapangan untuk praktik mengumpulkan data menggunakan GPS dan Field Papers. Peserta dibagi ke dalam 3 kelompok dimana dibagi dalam 3 area yang berbeda. Tiap kelompok didampingi oleh 1 orang trainer. Pelaksanaan survei lapangan berjalan dengan lancar dan semua peserta dapat menggunakan GPS dan Field Papers.

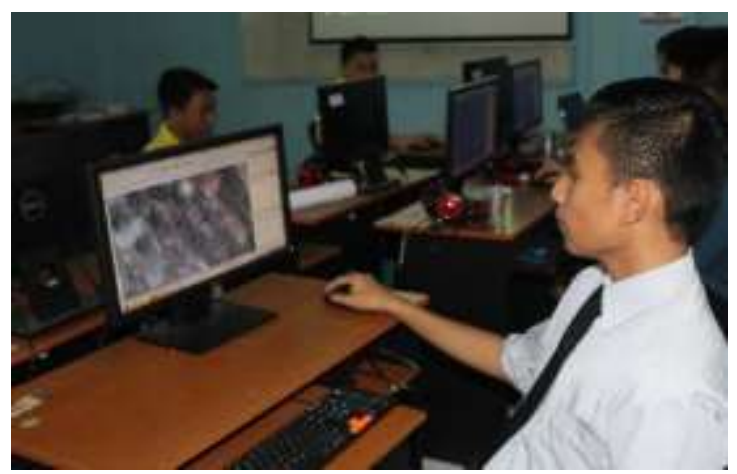

Gambar 8. Salah satu siswa sedang melakukan pendaftaran dan editing di OpenStreetMap.

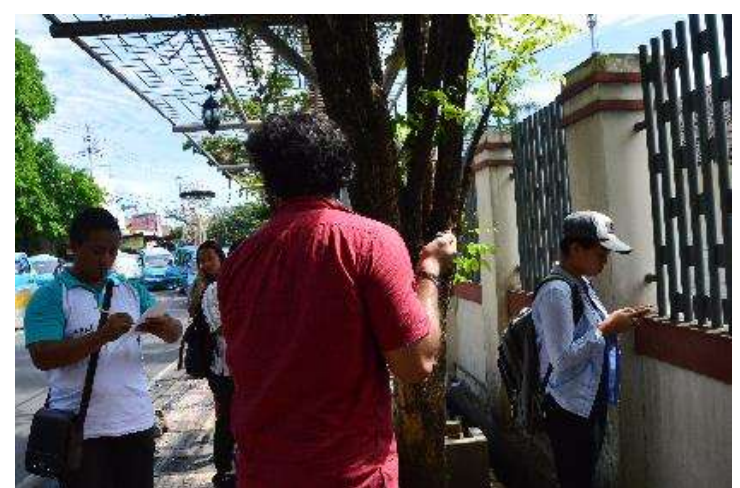

Gambar 9. Kegiatan lapangan dengan GPS.

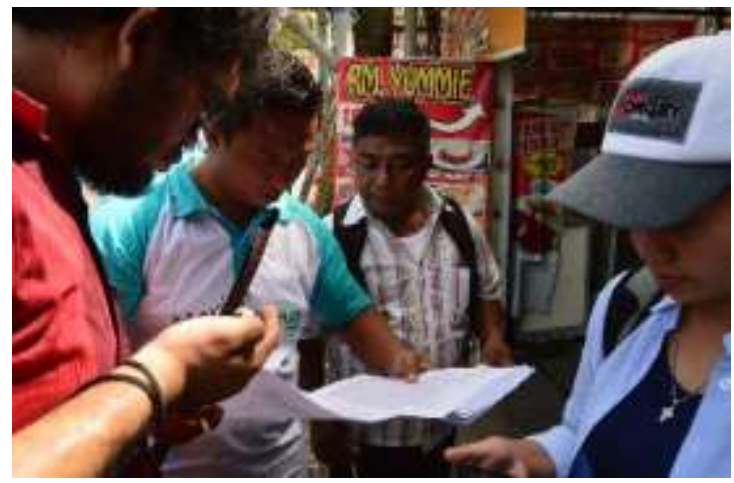

Gambar 10. Penggunaan field paper sebagai alat bantu dalam mengidentifikasi objek yang akan digambar.

Dalam survei lapangan ini para peserta mengumpulkan data-data fasilitas umum sepert rumah sakit, sekolah, kantor pemerintahan, pasar, dan lain-lain dengan 
memasukkan informasi seperti nama bangunan, tinggi bangunan, kapasitas ruangan, akses ke atap dan juga alamat bangunan. Setelah melaksanakan survey lapangan para peserta kemudian memasukkan data-data mereka ke dalam JOSM yang akan diedit dan diupload ke dalam situs OpenStreetMap.

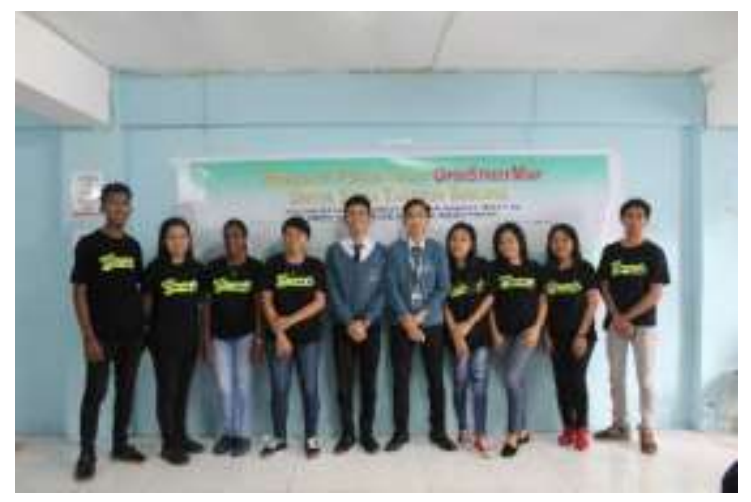

Gambar 11. Tim OpenStreetMap dan siswa selesai pelatihan.

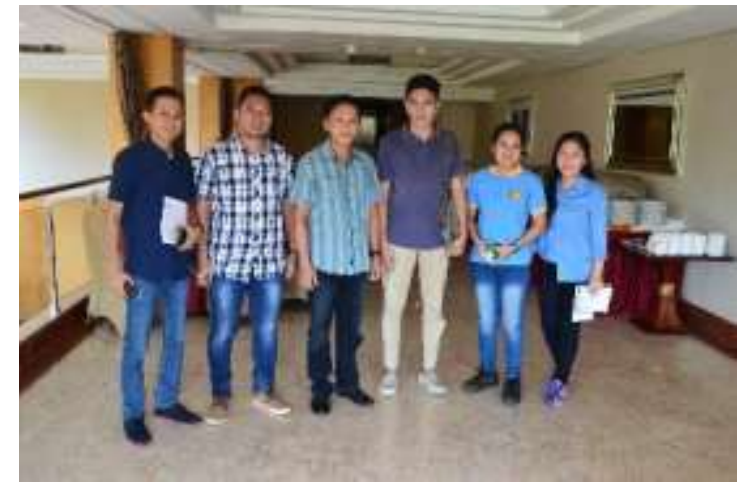

Gambar 12. Tim OpenStreetMap GeoUnima dengan Humanitarian OpenStreetMap Team dari Jakarta.

Secara umum pelaksanaan pelatihan OSM di SMU Prisma Manado berlangsung dengan baik dan lancar. Antusiasme peserta juga terlihat sangat baik dalam menerima materi yang disampaikan oleh para trainer. Para peserta terlihat aktif dalam menanggapi maupun memberikan pertanyaan terkait materi-materi yang disampaikan. Mereka berharap dapat lebih mengaplikasikan ilmu yang didapatkan kedepannya.

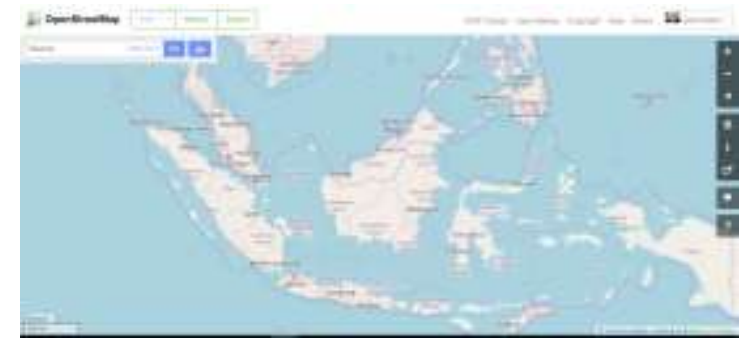

Gambar 13. Peta Indonesia di OpenStreetMap.

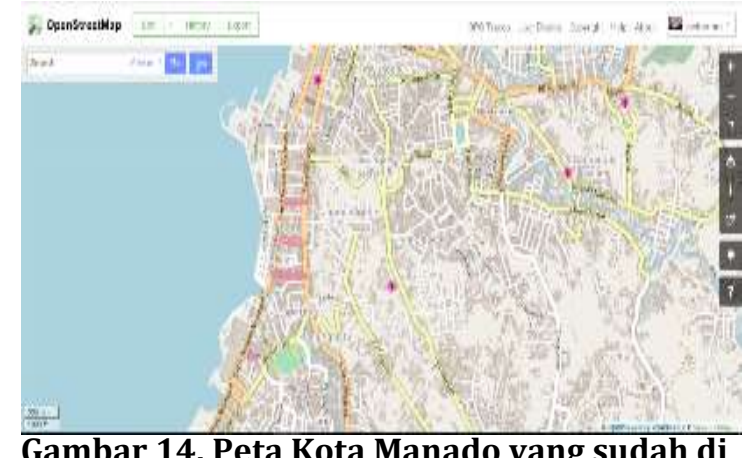
edit dengan OpenStreetMap.

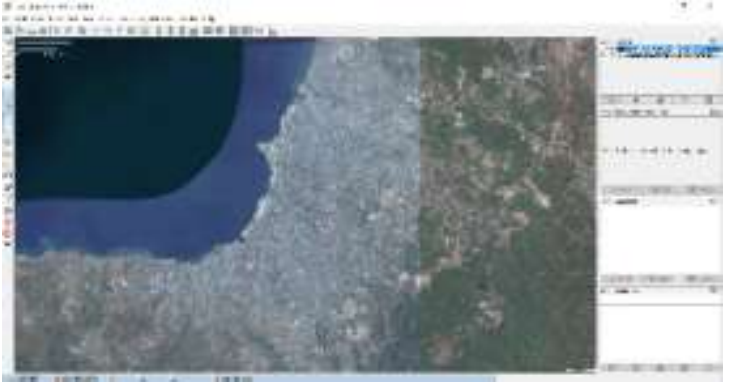

Gambar 15. Citra Satelit Kota Manado di OpenStreetMap.

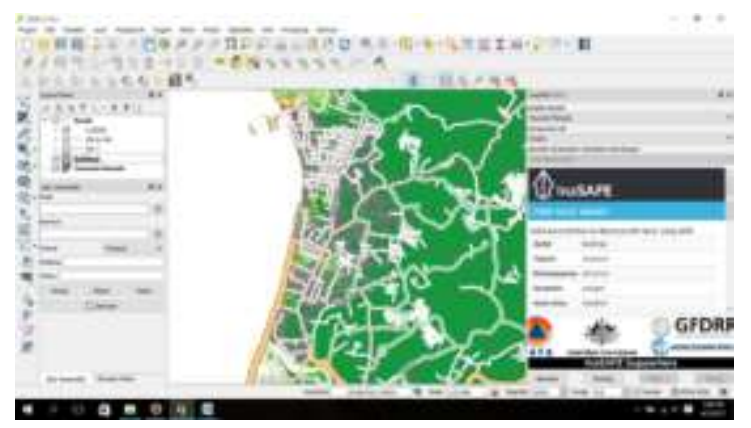

Gambar 16. Hasil digitasi peta di QGIS penentuan daerah rawan bencana. 


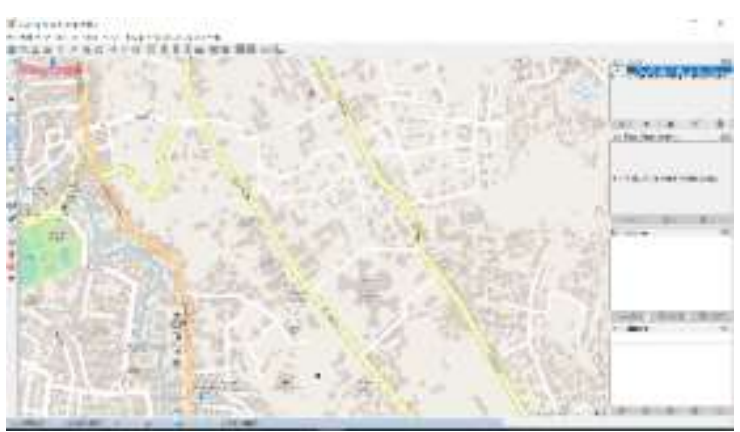

Gambar 17. Tampilan JOSM (Java

OpenStreetMap).

\section{KESIMPULAN}

Simpulan yang dapat diambil dari kegiatan pengabdian ini adalah: Siswa di SMU Prisma Kota Manado; pelatihan telah mendapatkan pengetahuan tentang peta digital dengan openstreetmap; Siswa di SMU Prisma Kota Manado telah memahami arti penting pembuatan peta digital dengan openstreetmap sebagai siswa tangguh bencana; Tersusunnya peta potensi infrastruktur dan peta potensi bencana di Kota Manado.

\section{KEPUSTAKAAN}

Girres, J. F., \& Touya, G. (2010). Quality assessment of the French OpenStreetMap dataset. Transactions in GIS, 14(4), 435-459.

Haklay, M. (2010). How good is volunteered geographical information? A comparative study of OpenStreetMap and Ordnance Survey datasets. Environment and planning B: Planning and design, 37(4), 682-703.

Haklay, M., \& Weber, P. (2008). Openstreetmap: User-generated street maps. IEEE Pervasive Computing, 7(4), 12-18.

Haklay, M., Antoniou, V., Basiouka, S., Soden, R., \& Mooney, P. (2014). Crowdsourced geographic information use in government. World Bank Publications.
Hartato, E. (2017). Volunteered geographic information (VGI) for disaster management: a case study for floods in Jakarta.

Kumaat, J. C. (2007). CAI: Media Pembelajaran Kontekstual Berbasis Informasi Teknologi.

Kumaat, J. C. (2013). Sistem Informasi Geografis: Suatu Pengantar Pemodelan Geografi. LP2AI. Universitas Negeri Manado.

Kumaat, J. C. (2014). Penginderaan Jauh :Teori dan Aplikasi. LP2AI. Universitas Negeri Manado.

Mooney, P., \& Corcoran, P. (2012). Characteristics of heavily edited objects in OpenStreetMap. Future Internet, 4(1), 285-305.

Mooney, P., Corcoran, P., \& Winstanley, A. C. (2010, November). Towards quality metrics for OpenStreetMap. In Proceedings of the 18th SIGSPATIAL international conference on advances in geographic information systems (pp. 514-517). ACM.

Olyazadeh, R., Aye, Z. C., Jaboyedoff, M., \& Derron, M. H. An Open-Source WebGIS Platform for Rapid Disaster Impact Assessment.

Pasi, R., Consonni, C., \& Napolitano, M. Open Community Data \& Official Public Data in flood risk management: a comparison based on InaSAFE.

Perdana, R. (2017). Penentuan Rute Perjalanan Menggunakan Algoritma A Star dengan Menggunakan Data Peta Openstreetmap untuk Digunakan pada Aplikasi Berbasis Android Clearroute (Doctoral dissertation, Institut Teknologi Sepuluh Nopember).

Pranantyo, I. R., Fadmastuti, M., \& Chandra, F. (2015, April). InaSAFE applications in disaster preparedness. In AIP Conference Proceedings (Vol. 1658, No. 1, p. 060001). AIP Publishing.

Putra, M. A., \& Whardana, A. K. (2017). Humanitarian OpenStreetMap Team Role Towards Mapping in Indonesia. 
IJTB (International Journal of Technology and Business), 1(1).

Ramm, F., Topf, J., \& Chilton, S. (2011). OpenStreetMap: using and enhancing the free map of the world. Cambridge: UIT Cambridge.

Yudono, A. (2017, June). Towards democracy in spatial planning through spatial information built by communities: The investigation of spatial information built by citizens from participatory mapping to volunteered geographic information in Indonesia. In IOP Conference Series: Earth and Environmental Science (Vol. 70, No. 1, p. 012002). 